\title{
D) Characteristics of those most vulnerable to OPEN ACCESS employment changes during the COVID-19 pandemic: a nationally representative cross-sectional study in Wales
}

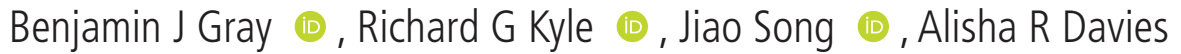

Research and Evaluation Division, Public Health Wales, Cardiff, UK

\section{Correspondence to} Dr Benjamin J Gray, Research and Evaluation Division, Public Health Wales, Cardiff CF10 4BZ, UK;

benjamin.gray@wales.nhs.uk

Received 10 November 2020 Accepted 20 June 2021 Published Online First 30 June 2021

\section{Check for updates}

(c) Author(s) (or their employer(s)) 2022. Re-use permitted under CC BY-NC. No commercial re-use. See rights and permissions. Published by BMJ.

To cite: Gray BJ, Kyle RG

Song J, et al. J Epidemiol

Community Health

2022; $76: 8-15$

\begin{abstract}
Background The public health response to the SARSCoV-2 (COVID-19) pandemic has had a detrimental impact on employment and there are concerns the impact may be greatest among the most vulnerable. We examined the characteristics of those who experienced changes in employment status during the early months of the pandemic.
\end{abstract}

Methods Data were collected from a cross-sectional, nationally representative household survey of the working age population (18-64 years) in Wales in May/June 2020 ( $n=1379)$. We looked at changes in employment and being placed on furlough since February 2020 across demographics, contract type, job skill level, health status and household factors. $\chi^{2}$ or Fisher's exact test and multinomial logistic regression models examined associations between demographics, subgroups and employment outcomes.

Results Of our respondents, $91.0 \%$ remained in the same job in May/June 2020 as they were in February $2020,5.7 \%$ were now in a new job and 3.3\% experienced unemployment. In addition, $24 \%$ of our respondents reported being placed on furlough. Nonpermanent contract types, individuals who reported low mental well-being and household financial difficulties were all significant factors in experiencing unemployment. Being placed on 'furlough' was more likely in younger (18-29 years) and older (60-64 years) workers, those in lower skilled jobs and from households with less financial security.

Conclusion A number of vulnerable population groups were observed to experience detrimental employment outcomes during the initial stage of the COVID-19 pandemic. Targeted support is needed to mitigate against both the direct impacts on employment, and indirect impacts on financial insecurity and health.

\section{INTRODUCTION}

Employment is a wider determinant of health, and the links between good employment and better health outcomes are well established. ${ }^{12}$ The response to the current global pandemic caused by SARS-CoV-2 (COVID-19) is already having a significant impact on people's ability to work and employment status.

Global estimates suggest that up to 25 million jobs could be lost as a result of the COVID-19 pandemic. ${ }^{3}$ Typically, mass unemployment events disproportionately impact the younger and older age groups, ${ }^{4-6}$ and those with lower skills or underlying health conditions are at more risk of exiting the labour market in the longer term. Compared with other Western countries, the USA and the UK have experienced more severe immediate labour market impacts. ${ }^{78}$ The unemployment rate in the USA was estimated to be $20 \%$ in April $2020,{ }^{7}$ and the unemployment rate in the UK reached a 3-year high of $4.5 \%$ in August 2020 . $^{9}$

More specifically, in the UK, a greater fall in working hours was experienced by younger workers and those without guaranteed work, ${ }^{10}$ while declines in earnings have been hardest felt by the most deprived ${ }^{10}$ and ethnic minority communities. ${ }^{1011}$ The introduction of economic interventions such as the Coronavirus Job Retention Scheme (also known as 'furlough') will moderate the rise in redundancies initially, but a significant rise in unemployment is inevitable. ${ }^{12}$ Predictions have suggested that job losses will be greatest within the retail and hospitality sectors ${ }^{13} 14$ and women, young people and the lowest paid are at particular risk of unemployment in this COVID-19 recession. ${ }^{14}$

Identifying the groups most vulnerable to changes in employment during the COVID-19 pandemic is important to better develop and target the health, re-employment and social support needed to prevent a longer term detrimental impact on societal health. ${ }^{4}$ Emerging UK research has raised concerns about the disproportionate impact on specific demographic groups, ${ }^{10} 1115$ while also commenting on regional disparities, ${ }^{15}$ suggesting a need for different approaches in the postpandemic recovery. We investigated the impact of COVID-19 on employment in the initial phases of the pandemic as well as observed differences by underlying health and household financial security in Wales.

\section{METHODS}

\section{Data source}

The data included in this study were collected from the COVID-19 Employment and Health in Wales Study, a nationally representative cross-sectional online household survey undertaken between 25 May 2020 and 22 June 2020.

\section{Participants}

Individuals were eligible to participate if they were resident in Wales, aged 18-64 years and in 
employment in February 2020. Those in full-time education or unemployed were not eligible to participate.

\section{Sample size calculation}

In order to ensure the sample was representative of the Welsh population, a stratified random probability sampling framework by age, gender and deprivation quintile was used. A target sample size of 1250 working age adults was set to provide an adequate sample across socioeconomic groups. To achieve a sample size of 1250 , a total of 20000 households were invited to participate. These invitation figures were based on the proportion of eligible working age households in Wales and informed by the most recent midyear population estimates and UK Labour Force Survey projections (figures for $2017^{16}{ }^{17}$ ). The 20000 sample included a main sample of 15000 and a boosted sample of 5000 of those in the lower deprivation quintiles to ensure representation from the most deprived populations.

\section{Recruitment}

Each selected household was sent a survey pack containing an invitation letter and participant information sheet. The invitation asked the eligible member of the household with the next birthday to participate in the survey. It included instructions on how to access the online questionnaire by entering a unique reference number provided in the letter. The letter highlighted the value of responding to the survey, that participation was voluntary and responses would be confidential, and provided an email address and freephone telephone number to contact for further information, to request to complete the questionnaire by an alternative method (telephone or postal) or to inform the project team that they did not wish to participate. Any individuals who informed the project team that they did not meet the inclusion criteria or opted out were removed from the reminder mailing, which was posted 10 days after the initial invitation.

In total, 1019 responses were received from the 15000 base sample (6.8\% response rate) and 273 responses received from the booster sample (5.5\% response rate) resulting in 1382 respondents $(6.9 \%$ overall response rate). The majority of the responses were online questionnaires (99.1\%), with an additional six paper and six telephone questionnaires. During data cleaning, individuals who had not completed the question on employment contract were excluded from the study, leaving a final sample of 1379 for analysis.

\section{Questionnaire measures}

The employment details were collected at the date of questionnaire completion in May/June 2020, and were at this point also retrospectively asked about their employment situation in February 2020. Questions on employment including contract type, rights and wages were based on the Employment Precariousness Scale ${ }^{18}$ and data on job role and associated skill level were determined using the current Standard Occupational Classification 2020 for the UK. ${ }^{19}$ Questions were asked on any employment changes experienced between February 2020 and May/June 2020; the outcomes of interest were: (1) same job; (2) new job, covering new job with same employer, new job with new employer and becoming self-employed; and (3) unemployment. In addition, respondents were also asked if they had been placed on furlough since February 2020.

Explanatory variables included: sociodemographics (gender, age group and deprivation quintile assigned based on postcode of residence using the Welsh Index of Multiple Deprivation ${ }^{20}$ ); individual self-reported health status including general health and pre-existing health conditions (defined using validated questions from the National Survey for Wales ${ }^{21}$ ) and mental well-being (determined using the short version of the WarwickEdinburgh Mental Well-being Scale ${ }^{22}$ ). We determined low mental well-being as $1 \mathrm{SD}$ below the mean score. Household factors were also collected including income covering basic needs ${ }^{18}$ and child(ren) in household. More detailed information on the questionnaire variables is provided in table 1 .

\section{Statistical analysis}

Data analysis on changes in employment was performed on the full sample $(n=1379)$. Not all respondents answered the question on furlough and any individuals who answered 'don't know' were also excluded from the furlough analysis, leaving a subsample of 1159. To examine differences in employment outcomes across population groups, we tested the relationships between changes in employment or furlough and the explanatory variables using $\chi^{2}$ test or Fisher's exact test, respectively. Multinomial logistic regression models were used to identify characteristics associated with changes in employment. Binary logistic regression was performed to identify characteristics associated with furlough. These results are reported as adjusted ORs (aOR) and 95\% CIs. A p value $<0.05$ was considered statistically significant. To supplement our multinomial logistic regression analysis, we explored the relationship between employment changes and contract type further through computing predicted probabilities while setting the remaining variables to their central measures.

\section{RESULTS}

\section{Sample demographics}

For reference, the demographic (gender, age, deprivation quintile) details of our 'working age' sample are compared with the latest Welsh population (midyear 2018 population estimates ${ }^{17}$ ) in table 2. Although broadly representative overall, compared with the Welsh population, females and the older age groups are overrepresented in our sample.

\section{Changes in employment status}

Our findings suggest that $91.0 \%$ of the Welsh working age population were in the same job in May/June 2020 as they were in February 2020, 5.7\% were now in a new job and 3.3\% have experienced unemployment (table 3 ). There was no statistically significant difference observed in changes in employment by gender, age or deprivation quintile demographics (table 3). Changes in employment were more apparent in those employed on nonpermanent contracts $(\mathrm{p}<0.001$; table 3$)$, where job losses were experienced more by those employed on an atypical contract (12.1\%), fixed-term contract $(7.7 \%)$ and also those who were self-employed (9.3\%) compared with those employed on permanent arrangements $(1.8 \%$; table 3$)$. Unemployment was higher among those reporting financial difficulties in meeting basic needs $(6.3 \%)$ compared with $2.2 \%$ of those with no financial struggles $(\mathrm{p}<0.001$; table 3$)$ and also in those experiencing poorer mental health outcomes (low mental well-being: 11.5\% compared with average mental well-being: $2.5 \%$; $<<0.001$; table 3 ).

\section{Characteristics of those furloughed}

Considering demographics, the proportion of respondents placed on furlough was highest in the youngest age group (18-29 years; $37.8 \%$ ), decreasing to $18.8 \%$ in the $40-49$ years age group and increasing to $29.6 \%$ in the $60-64$ years age group $(\mathrm{p}<0.001$; table 3 ). The highest proportion on furlough was evident among the most deprived communities (30.3\%) and declined as a gradient 
Table 1 Measures for variables included in the national survey

\begin{tabular}{|c|c|c|}
\hline Measure & Source & Classification \\
\hline Employment contract & $\begin{array}{l}\text { Employment Precariousness } \\
\text { Scale (EPRES) }\end{array}$ & $\begin{array}{l}\text { Permanent (permanent contract) } \\
\text { Fixed term (fixed term, } 1 \text { year or more; fixed term, between } 6 \text { and } 12 \text { months; fixed term, less than } 6 \text { months) } \\
\text { Atypical (temporary, no fixed term; zero-hour contract; do not have a contract) } \\
\text { Self-employed (self-employed) }\end{array}$ \\
\hline $\begin{array}{l}\text { Employment skill level } \\
\text { (hierarchy) }\end{array}$ & $\begin{array}{l}\text { Office for National } \\
\text { Statistics-SOC 2020 }\end{array}$ & $\begin{array}{l}\text { Employment skill level } 4 \text { (corporate managers and directors; science, research, engineering and technology } \\
\text { professionals; health professionals; teaching and other educational professionals; business, media and public service } \\
\text { professionals) } \\
\text { Employment skill level } 3 \text { (other managers and proprietors; science, engineering and technology associate } \\
\text { professionals; health and social care associate professionals; protective service occupations; culture, media and sports } \\
\text { occupations; business and public service associate professionals; skilled agricultural and related trades; skilled metal, } \\
\text { electrical and electronic trades; skilled construction and building trades; textiles, printing and other skilled trades) } \\
\text { Employment skill level } 2 \text { (administrative occupations; secretarial and related occupations; caring personal service } \\
\text { occupations; leisure, travel and related personal occupations; community and civil enforcement occupations; sales } \\
\text { occupations; customer service occupations; process, plant and machine operatives; transport and mobile machine } \\
\text { drivers and operatives) } \\
\text { Employment skill level } 1 \text { (elementary trades and related occupations; elementary administration and service } \\
\text { occupations) }\end{array}$ \\
\hline Mental well-being & $\begin{array}{l}\text { Warwick-Edinburgh Mental } \\
\text { Well-being Scale (short } \\
\text { version) }\end{array}$ & Raw scores were converted into metric scores and categorised as average or low mental well-being. \\
\hline Household income & EPRES $^{18}$ & $\begin{array}{l}\text { Does your total household income allow you to cover your basic needs? (food, shelter and warmth) } \\
\text { Always covers basic needs (always) } \\
\text { Does not cover basic needs (most of the time, sometimes, rarely, never) }\end{array}$ \\
\hline Child(ren) in household & Internal question & $\begin{array}{l}\text { How many children live with you in the following age bands? (enter a number) } \\
\text { (A) } 0-1 \text { year old; (B) } 2-4 \text { years old; (C) primary school age (5-10 years old); (D) secondary school age (11-17 years old) } \\
\text { No child(ren) in household (total is zero) } \\
\text { Child(ren) in household (total is } 1 \text { or more) }\end{array}$ \\
\hline
\end{tabular}

SOC, Standard Occupational Classification.

across deprivation quintiles to $17.6 \%$ in the least deprived $(\mathrm{p}=0.015$; table 3$)$.

Employment characteristics also impacted on being placed on furlough, lowest skill workers (35.4\%) had the highest proportions 'furloughed' and this also decreased as a gradient with increasing skill level to $12.9 \%$ among the highest skilled workers $(\mathrm{p}<0.001$;

Table 2 Survey population and Welsh population estimate (midyear 2018) comparisons

\begin{tabular}{llll}
\hline & \multicolumn{1}{c}{ Survey population } & & Welsh population \\
\cline { 2 - 2 } & $\mathbf{n}(\%)$ & $\mathbf{n}(\%)$ \\
\hline All & 1379 & 1856853 \\
\hline Males & $542(39.3)$ & $924020(49.8)$ \\
\hline Females & $823(59.7)$ & $932833(50.2)$ \\
\hline Not provided & $14(1.0)$ & \\
\hline 18-29 years & $157(11.4)$ & $485909(26.2)$ \\
\hline 30-39 years & $271(19.7)$ & $371851(20.0)$ \\
\hline 40-49 years & $338(24.5)$ & $375526(20.2)$ \\
\hline 50-59 years & $416(30.2)$ & $433915(23.4)$ \\
\hline 60-64 years & $177(12.8)$ & $189652(10.2)$ \\
\hline Not provided & $20(1.4)$ & \\
\hline Quintile 1 (high deprivation) & $258(18.7)$ & $371014(20.0)$ \\
\hline Quintile 2 & $326(23.6)$ & $370637(20.0)$ \\
\hline Quintile 3 & $228(16.5)$ & $384927(20.7)$ \\
\hline Quintile 4 & $254(18.4)$ & $370242(19.9)$ \\
\hline Quintile 5 (low deprivation\} & $313(22.7)$ & $360033(19.4)$ \\
\hline
\end{tabular}

table 3). People with atypical working arrangements experienced the highest proportions of being placed on furlough $(42.6 \%$; table 3). A higher proportion of households struggling to cover basic financial needs also had been placed on furlough compared with those households reporting no financial difficulties $(32.2 \%$ compared with $20.7 \%$; $<0.001$ ).

\section{Predictors of changes in employment situation and 'furlough'}

Younger people aged $18-29$ years (aOR 2.5; 95\% CI 1.5 to 4.3 ) and older people aged $60-64$ years (aOR 2.2 ; 95\% CI 1.3 to 3.8 ) were more likely to experience furlough compared with the 40-49 years age group (table 4). Skill level was also a significant predictor of furlough, with those working in lower skilled roles more likely to have been placed on furlough compared with the highest skilled jobs (job skill 1: aOR 3.3; 95\% CI 1.6 to 6.9 ; job skill 2: aOR 3.2; $95 \%$ CI 2.2 to 4.7 ; job skill 3: aOR 2.7; $95 \%$ CI 1.8 to 4.1 ; table 4). Individuals who experienced financial difficulties (aOR $1.9 ; 95 \%$ CI 1.4 to 2.6 ) were also more likely to have been placed on furlough (table 4). Those who were self-employed (aOR 0.3; $95 \%$ CI 0.2 to 0.6 ) or who reported having 'not good' general health (aOR 0.6 ; 95\% CI 0.4 to 0.9 ) were less likely to have been placed on furlough (table 4).

Compared with permanent employment, the aORs were distinctly higher for experiencing unemployment in all other contract types (atypical employment: aOR 11.9; 95\% CI 4.3 to 32.9; fixed-term contracts: aOR 4.4 ; $95 \%$ CI 1.3 to 14.8 ; selfemployed: aOR 6.2; 95\% CI 2.7 to 14.1 ; table 4). In addition, those on atypical working arrangements (aOR 3.7; 95\% CI 1.5 to 9.1) and holding fixed-term contracts (aOR 2.6; 95\% CI 1.1 to 6.3) were more likely to have changed jobs. The computed 
Table 3 The share of employment changes experienced by sociodemographics, wider determinants, health status and results of $\chi^{2}$ statistics

\begin{tabular}{|c|c|c|c|c|}
\hline & \multicolumn{3}{|c|}{$\begin{array}{l}\text { Changes in employment } \\
\qquad n=1379\end{array}$} & \multirow{2}{*}{$\begin{array}{l}\text { 'Furloughed' } \\
\mathrm{n}=1159\end{array}$} \\
\hline & Same job & New job & Unemployed & \\
\hline All & $91.0 \%$ & $5.7 \%$ & $3.3 \%$ & $24.0 \%$ \\
\hline \multicolumn{5}{|l|}{ Gender } \\
\hline Male & $91.5 \%$ & $4.6 \%$ & $3.9 \%$ & $26.0 \%$ \\
\hline Female & $90.8 \%$ & $6.4 \%$ & $2.8 \%$ & $23.0 \%$ \\
\hline$P$ value & & 0.211 & & 0.243 \\
\hline \multicolumn{5}{|l|}{ Age group (years) } \\
\hline $18-29$ & $87.3 \%$ & $7.6 \%$ & $5.1 \%$ & $37.8 \%$ \\
\hline $30-39$ & $91.5 \%$ & $5.5 \%$ & $3.0 \%$ & $24.7 \%$ \\
\hline $40-49$ & $90.2 \%$ & $5.9 \%$ & $3.8 \%$ & $18.8 \%$ \\
\hline $50-59$ & $90.9 \%$ & $5.8 \%$ & $3.4 \%$ & $20.2 \%$ \\
\hline $60-64$ & $94.9 \%$ & $3.4 \%$ & $1.7 \%$ & $29.6 \%$ \\
\hline$P$ value & & 0.587 & & $<0.001$ \\
\hline \multicolumn{5}{|l|}{ Deprivation } \\
\hline Quintile 1 (most deprived) & $92.7 \%$ & $5.0 \%$ & $2.3 \%$ & $30.3 \%$ \\
\hline Quintile 2 & $91.7 \%$ & $5.2 \%$ & $3.1 \%$ & $26.7 \%$ \\
\hline Quintile 3 & $90.4 \%$ & $6.1 \%$ & $3.5 \%$ & $24.0 \%$ \\
\hline Quintile 4 & $88.2 \%$ & $7.5 \%$ & $4.3 \%$ & $22.0 \%$ \\
\hline Quintile 5 (least deprived) & $91.7 \%$ & $4.8 \%$ & $3.5 \%$ & $17.6 \%$ \\
\hline$P$ value & & 0.830 & & 0.015 \\
\hline \multicolumn{5}{|l|}{ Employment contract } \\
\hline Permanent & $93.6 \%$ & $4.6 \%$ & $1.8 \%$ & $25.1 \%$ \\
\hline Fixed term & $81.5 \%$ & $10.8 \%$ & $7.7 \%$ & $19.2 \%$ \\
\hline Atypical & $74.1 \%$ & $13.8 \%$ & $12.1 \%$ & $42.6 \%$ \\
\hline Self-employed & $82.7 \%$ & $8.0 \%$ & $9.3 \%$ & $10.9 \%$ \\
\hline$P$ value & & $<0.001$ & & $<0.001$ \\
\hline \multicolumn{5}{|l|}{ Employment hierarchy } \\
\hline Job skill level 4 & $93.4 \%$ & $4.2 \%$ & $2.4 \%$ & $12.9 \%$ \\
\hline Job skill level 3 & $89.2 \%$ & $6.2 \%$ & $4.5 \%$ & $27.4 \%$ \\
\hline Job skill level 2 & $89.3 \%$ & $6.9 \%$ & $3.8 \%$ & $33.8 \%$ \\
\hline Job skill level 1 & $92.6 \%$ & $5.6 \%$ & $1.9 \%$ & $35.4 \%$ \\
\hline$P$ value & & 0.269 & & $<0.001$ \\
\hline \multicolumn{5}{|l|}{ Household total income } \\
\hline Always covers basic needs & $92.6 \%$ & $5.2 \%$ & $2.2 \%$ & $20.7 \%$ \\
\hline Does not always cover basic needs & $86.7 \%$ & $7.0 \%$ & $6.3 \%$ & $32.2 \%$ \\
\hline$P$ value & & $<0.001$ & & $<0.001$ \\
\hline \multicolumn{5}{|l|}{ Family unit } \\
\hline No child in household & $90.6 \%$ & $6.1 \%$ & $3.3 \%$ & $24.4 \%$ \\
\hline Child in household & $91.7 \%$ & $4.9 \%$ & $3.4 \%$ & $23.3 \%$ \\
\hline$P$ value & & 0.681 & & 0.684 \\
\hline \multicolumn{5}{|l|}{ Health status } \\
\hline No pre-existing condition & $91.8 \%$ & $4.8 \%$ & $3.4 \%$ & $22.3 \%$ \\
\hline Pre-existing condition & $89.6 \%$ & $7.3 \%$ & $3.1 \%$ & $26.6 \%$ \\
\hline Not sure & $91.5 \%$ & $5.6 \%$ & $2.8 \%$ & $27.1 \%$ \\
\hline$P$ value & & 0.468 & & 0.244 \\
\hline \multicolumn{5}{|l|}{ General health status } \\
\hline Good or better & $91.1 \%$ & $5.8 \%$ & $3.0 \%$ & $24.1 \%$ \\
\hline Not good & $90.9 \%$ & $4.7 \%$ & $4.3 \%$ & $22.8 \%$ \\
\hline$P$ value & & 0.427 & & 0.694 \\
\hline \multicolumn{5}{|l|}{ Mental health } \\
\hline Average mental well-being & $91.9 \%$ & $5.6 \%$ & $2.5 \%$ & $22.9 \%$ \\
\hline Low mental well-being & $84.9 \%$ & $3.6 \%$ & $11.5 \%$ & $31.3 \%$ \\
\hline$P$ value & & $<0.001$ & & 0.05 \\
\hline
\end{tabular}

Bold figures denote significant observations $(p<0.05)$. 
Table 4 Predictors of employment changes experienced in the early months of the COVID-19 pandemic

\begin{tabular}{|c|c|c|c|}
\hline \multirow[b]{2}{*}{ Predictors } & \multicolumn{2}{|c|}{$\begin{array}{l}\text { Change in employment status } \\
n=1379\end{array}$} & \multirow{2}{*}{$\begin{array}{l}\text { 'Furloughed' } \\
\mathrm{n}=1159\end{array}$} \\
\hline & Now unemployed versus same job & New job versus same job & \\
\hline \multicolumn{4}{|l|}{ Gender } \\
\hline Male & Reference & Reference & Reference \\
\hline Female & $1.0(0.5$ to 2.0$)$ & $1.4(0.8$ to 2.4$)$ & $0.8(0.6$ to 1.2$)$ \\
\hline \multicolumn{4}{|l|}{ Age group (years) } \\
\hline $30-39$ & $1.1(0.4$ to 2.9$)$ & $1.0(0.5$ to 2.1$)$ & $1.4(0.9$ to 2.3$)$ \\
\hline $40-49$ & Reference & Reference & Reference \\
\hline $50-59$ & 0.7 (0.3 to 1.8$)$ & $0.8(0.4$ to 1.5$)$ & $1.3(0.8$ to 2.0$)$ \\
\hline $60-64$ & $0.4(0.1$ to 1.7$)$ & 0.3 (0.1 to 0.9$)$ & $2.2(1.3$ to 3.8$)$ \\
\hline \multicolumn{4}{|l|}{ Deprivation } \\
\hline Quintile 5 (least deprived) & Reference & Reference & Reference \\
\hline \multicolumn{4}{|l|}{ Employment contract } \\
\hline Permanent & Reference & Reference & Reference \\
\hline Fixed term & $4.4(1.3$ to 14.8$)$ & 2.6 (1.1 to 6.3$)$ & $0.6(0.3$ to 1.3$)$ \\
\hline Atypical & $11.9(4.3$ to 32.9$)$ & 3.7 (1.5 to 9.1$)$ & 1.8 (0.96 to 3.3$)$ \\
\hline Self-employed & $6.2(2.7$ to 14.1$)$ & $1.9(0.9$ to 4.1$)$ & $0.3(0.2$ to 0.6$)$ \\
\hline \multicolumn{4}{|l|}{ Employment hierarchy } \\
\hline Job skill level 4 & Reference & Reference & Reference \\
\hline Job skill level 3 & $1.6(0.7$ to 3.7$)$ & $1.6(0.8$ to 3.0$)$ & $2.7(1.8$ to 4.1$)$ \\
\hline Child in household & $1.1(0.5$ to 2.4$)$ & $0.7(0.4$ to 1.3$)$ & 1.3 (0.9 to 1.8$)$ \\
\hline \multicolumn{4}{|l|}{ Health status } \\
\hline No pre-existing condition & Reference & Reference & Reference \\
\hline Pre-existing condition & $0.7(0.3$ to 1.5$)$ & 1.7 (1.0 to 3.07 ) & $1.4(1.0$ to 1.9$)$ \\
\hline Not sure & $0.5(0.1$ to 2.3$)$ & $1.0(0.3$ to 3.4$)$ & 1.1 (0.5 to 2.1$)$ \\
\hline \multicolumn{4}{|l|}{ General health status } \\
\hline Good or better & Reference & Reference & Reference \\
\hline Not good & $1.2(0.5$ to 2.7$)$ & 0.7 (0.4 to 1.5$)$ & $0.6(0.4$ to 0.9$)$ \\
\hline \multicolumn{4}{|l|}{ Mental health } \\
\hline Average mental well-being & Reference & Reference & Reference \\
\hline Low mental well-being & 4.1 (1.9 to 9.0$)$ & $0.6(0.2$ to 1.5$)$ & 1.3 (0.8 to 2.2 ) \\
\hline
\end{tabular}

Data reported as adjusted ORs (aOR) and $95 \%$ Cls. Bold figures denote significant observations $(\mathrm{p}<0.05)$.

predicted probabilities of falling into each of the three employment change categories were calculated among the different contract types (table 5). These figures demonstrate further that job insecurity (changing jobs or becoming unemployed) is higher among those individuals holding non-permanent contracts. Furthermore, individuals who reported low mental well-being (aOR 4.1; 95\% CI 1.9 to 9.0 ) or experienced financial difficulties (aOR 2.1; $95 \%$ CI 1.1 to 4.3 ) were also more likely to experience unemployment (table 4).

\section{DISCUSSION}

This study reports findings from the first nationally representative survey in Wales that examines the associations between sociodemographics, wider determinants, underlying health status and employment outcomes during the COVID-19 pandemic. The findings provide unique insights into the population groups experiencing societal harms ${ }^{23}$ as a result of the indirect effect of COVID-19 on employment. People who are younger (18-29 
Table 5 Predicted probabilities derived from multinomial logistic regression for employment changes experienced by contract type

\begin{tabular}{llll}
\hline & \multicolumn{3}{c}{$\begin{array}{c}\text { Changes in employment } \\
\mathrm{n}=1379\end{array}$} \\
\cline { 2 - 4 } & Same job & New job & Unemployed \\
\hline Employment contract (\%) & & & \\
\hline Permanent & 96.8 & 2.6 & 0.6 \\
\hline Fixed term & 90.9 & 6.3 & 2.8 \\
\hline Atypical & 84.7 & 8.4 & 6.9 \\
\hline Self-employed & 91.5 & 4.6 & 3.9 \\
\hline
\end{tabular}

years), older (60-64 years), living in the most deprived communities, employed on non-permanent contracts, low-skilled workers and those with less financial security are more likely to experience employment harms as a result of the COVID-19 pandemic. Our study therefore identifies vulnerable groups that are 'at risk' of future job losses, and also reveals the disproportionate experiences of population subgroups in relation to unemployment experienced in the early part of the pandemic.

These findings are consistent with early evidence from other parts of the UK in relation to the at-risk populations that have been furloughed, notably those in certain age groups (18-29 years and 60 years and older) and those in lower skilled jobs. ${ }^{13}{ }^{14}$ Of concern, however, is the disproportionate impact on vulnerable groups in the population that are currently supported by the Coronavirus Job Retention Scheme ('furlough'). Not all individuals placed on furlough (and subsequent job retention schemes) will ultimately lose their jobs, but there is the potential for the impact on employment and health to be greatest among the most vulnerable subpopulations when this scheme ceases. ${ }^{12}$ Evidence indicates that pandemics have the potential to exacerbate inequalities, ${ }^{6} 24$ especially within the most deprived communities, and our findings suggest COVID-19 will have a similar impact. One of the more striking observations is the unequal impacts of employment changes on those people employed on non-permanent contract arrangements. Existing research from the early months of the pandemic has also reported that those with temporary contracts were more likely to have experienced unemployment as a result of the coronavirus shock. ${ }^{8}$ In recent decades, employment trends have seen a marked increase in flexible, non-standard arrangements; contributing to reduced job security reduced income security, and increased temporary contracts. ${ }^{25} 26$ It is well documented that these precarious employment arrangements are more commonplace within younger, migrant and female subpopulations, and there is growing evidence to suggest there are negative impacts on health. ${ }^{26}{ }^{27}$ Those on atypical and fixed-term contracts were also more likely to have changed jobs since February 2020, longitudinal research is required to assess the quality of this new employment and the potential longer term implications on health.

Unemployment is also known to have a negative impact on an individual's own health, such as poorer mental health outcomes. ${ }^{2829}$ Our data confirm this association. This worrying finding warrants further investigation and intervention as, although causality cannot be established through our study, it may reflect a consequence of unemployment or furlough during the pandemic rather than a preexisting state. However, research has suggested that mental health in the UK has deteriorated compared with pre-COVID trends. ${ }^{30}$ Being, or in the case of our study, becoming unemployed during a recession can worsen levels of psychological distress. ${ }^{31} 32$ Our findings also suggest that those with pre-existing health conditions disproportionately experienced job loss in the early part of the pandemic. This echoes a pre-COVID European study where those with poorer mental and physical health were at greater risk of job losses. ${ }^{33}$ Addressing poorer health outcomes associated with poverty was already a public health priority before the COVID-19 pandemic. ${ }^{34} 35$ Our results suggest households struggling financially to meet basic needs have been disproportionately impacted by unemployment during the early part of the pandemic, and this may have potential to cause wider harm to other members in the household. ${ }^{3637}$

Our study helps to inform strategies and interventions to support vulnerable groups who have already disproportionately experienced harm from the early part of the pandemic and more importantly, re-emphasises the importance of permanent contract arrangements to negate adverse impacts of economic shocks. Uncertainties surrounding the global post-COVID labour market remain and although job retention schemes in place in many countries across the world still have some months to run these are economic rather than health-driven solutions. The potential for long-term negative impacts on health and well-being is evident in our study and health-aligned solutions may be required to mitigate these negative consequences. It is also important to remember that job insecurity itself, even if only perceived, can also have negative health consequences. ${ }^{38} 39$ Furthermore, given poverty and health are inextricably linked, ${ }^{34-37}$ the higher levels of furlough we observed among households who reported struggling financially to cover basic needs require attention. Social support systems and targeted initiatives to address inequalities in access to the labour market are needed by those potentially facing unemployment. Our study underscores the need to draw public health professionals and practices into the heart of debates around economic recovery and restructuring to ensure wider determinants of health and health inequalities are addressed. ${ }^{40}$

\section{Study limitations}

Our study has three main limitations. First, the cross-sectional design of the survey means that the observations demonstrate an association rather than causality. For example, caution is needed in interpretation of some of the findings in relation to mental wellbeing due to the data collection being at one time point and it is not known if low mental well-being was evident before. As noted, it has been observed that trends in UK mental health have worsened from pre-COVID levels. ${ }^{30}$ Second, employment changes were a relatively rare event during the early stages of the pandemic; although this manuscript clearly demonstrates some important findings, some of the aORs should be interpreted with caution. To this end, for a more nuanced interpretation, we included predicted probabilities of falling into each of the three employment change status among people holding different types of contracts. Despite the low likelihood of job loss, employees on atypical contracts are at increased risk over other types of contracts. Finally, although designed to be representative to the population, females and the older age groups are over-represented in our sample compared with the Welsh population, whereas deprivation quintiles are broadly representative except for the middle to high quintiles (quintiles 3 and 4). However, the consistencies within our data and national data (where comparators are available) suggest that our findings are generalisable. Future studies that examine the longer term impacts of COVID-19 on employment and health could adopt a household door-to-door approach (if restrictions allow) to improve response rate and representativity.

\section{CONCLUSION}

Unemployment in the early months of the COVID-19 pandemic impacted most on individuals in non-permanent work and those 
experiencing poorer mental well-being or financial difficulties. Furlough disproportionately impacted several population groups including the youngest (18-29 years) and oldest (60-64 years) age groups, people living in deprived communities, those employed in lower skilled job roles and people struggling financially. A social gradient was observed across deprivation and worker skill level with those living in the most deprived areas and working in the lowest skilled jobs more likely to be furloughed. Interventions to support economic recovery need to target the groups identified here as most susceptible to the emerging harms of the pandemic. Our study also strongly emphasises the importance of good, secure employment to survive economic shocks and protect individuals from the negative harms of unemployment.

\section{What is already known on this subject}

- The response to the current global pandemic caused by SARS-CoV-2 (COVID-19) is already having a significant impact on people's ability to work and employment status.

- Emerging UK employment data have raised concerns about the disproportionate impact on specific demographic groups.

\section{What this study adds}

- Groups that reported higher proportions of being placed on furlough included younger (18-29 years) and older (50-64 years) workers, people from more deprived areas, in lower skilled jobs and those from households with less financial security.

- Job insecurity in the early months of the COVID-19 pandemic was experienced more by those self-employed or employed on atypical or fixed-term contract arrangements compared with those holding permanent contracts.

- To ensure that health and wealth inequalities are not exacerbated by COVID-19 or the economic response to the pandemic, interventions should include the promotion of secure employment and target the groups identified as most susceptible to the emerging harms of the pandemic.

Twitter Benjamin J Gray @dr_benjamin23, Richard G Kyle @richardgkyle, Jiao Song @jsongwales and Alisha R Davies @AlishaDavies1

Acknowledgements The authors express their gratitude to MEL Research who completed the data collection for this study and to the people from across Wales who completed the survey. We would also like to acknowledge the contribution of our colleague James Bailey for his assistance in the initial stages of the manuscript.

Contributors BJG, RGK and ARD all made substantial contributions to the conception and design of the work. JS made substantial contributions to the data analysis. All authors made substantial contributions to the interpretation of the data. BJG drafted the manuscript. RGK, JS and ARD all critically appraised the intellectual content and contributed to the editing and revision of the manuscript. All authors gave approval to the final version and agree to be accountable for all aspects of the work.

Funding The authors have not declared a specific grant for this research from any funding agency in the public, commercial or not-for-profit sectors.

Competing interests None declared.

Patient consent for publication Not required.

Ethics approval The Health Research Authority approved the study (IRAS: 282223)

Provenance and peer review Not commissioned; externally peer reviewed.

Data availability statement No data are available. Owing to the nature of this research, participants of this study did not agree for their data to be shared publicly.

Open access This is an open access article distributed in accordance with the Creative Commons Attribution Non Commercial (CC BY-NC 4.0) license, which permits others to distribute, remix, adapt, build upon this work non-commercially, and license their derivative works on different terms, provided the original work is properly cited, appropriate credit is given, any changes made indicated, and the use is non-commercial. See: http://creativecommons.org/licenses/by-nc/4.0/.

\section{ORCID iDs}

Benjamin J Gray http://orcid.org/0000-0003-1548-707X

Richard G Kyle http://orcid.org/0000-0002-6394-109X

Jiao Song http://orcid.org/0000-0002-4976-156X

\section{REFERENCES}

1 Van Aerden K, Puig-Barrachina V, Bosmans K, et al. How does employment quality relate to health and job satisfaction in Europe? A typological approach. Soc Sci Med 2016;158:132-40.

2 van der Noordt M, IJzelenberg H, Droomers M, et al. Health effects of employment: a systematic review of prospective studies. Occup Environ Med 2014;71:730-6.

3 International Labour Organization. COVID-19 and the world of work: impact and policy responses, 2020. Available: https://www.ilo.org/wcmsp5/groups/public/dgreports/-dcomm/documents/briefingnote/wcms_738753.pdf [Accessed 15 Oct 2020].

4 Davies AR, Homolova L, Grey CNB, et al. Health and mass unemployment events - developing a framework for preparedness and response. J Public Health 2019;41:665-73.

5 Bell DNF, Blanchflower DG. Uk unemployment in the great recession. Natl Inst Econ Rev 2010;214:R3-25.

6 Lee A, Cho J. The impact of epidemics on labor market: identifying victims of the middle East respiratory syndrome in the Korean labor market. Int J Equity Health 2016:15:1-15

7 Bell DNF, Blanchflower DG. Us and UK labour markets before and during the COVID-19 crash. Natl Inst Econ Rev 2020;252:R52-69.

8 Adams-Prassl A, Boneva T, Golin M, et al. Inequality in the impact of the coronavirus shock: evidence from real time surveys. J Public Econ 2020;189:104245.

9 Office for National Statistics. Unemployment rate (aged 16 and over, seasonally adjusted) - 13th October, 2020. Available: https://www.ons.gov.uk/employmentan dlabourmarket/peoplenotinwork/unemployment/timeseries/mgsx/lms [Accessed 28 Oct 2020].

10 Crossley TF, Fisher $\mathrm{P}$, Low $\mathrm{H}$. The heterogeneous and regressive consequences of COVID-19: evidence from high quality panel data. J Public Econ 2021;193:104334.

$11 \mathrm{Hu}$ Y. Intersecting ethnic and native-migrant inequalities in the economic impact of the COVID-19 pandemic in the UK. Res Soc Stratif Mobil 2020:68:100528.

12 Mayhew K, Anand P. COVID-19 and the UK labour market. Oxf Rev Econ Policy 2020;36:\$215-24

13 Wilson T, Cockett J, Papoutsaki D. Getting back to work, 2020. Available: https:// www.employment-studies.co.uk/resource/getting-back-work-0 [Accessed $29 \mathrm{Sep}$ 2020].

14 Gardiner L, Slaughter $\mathrm{H}$. The effects of the coronavirus crisis on workers Flash findings from the Resolution Foundation's coronavirus survey, 2020. Available: https://www. resolutionfoundation.org/app/uploads/2020/05/The-effect-of-the-coronavirus-crisison-workers.pdf [Accessed 29 Sep 2020].

15 Mikolai J, Keenan K, Kulu H. Intersecting household-level health and socio-economic vulnerabilities and the COVID-19 crisis: an analysis from the UK. SSM Popul Health 2020;12:100628-8273.

16 Office for National Statistics. Labour force survey. Available: https://www.ons.gov. uk/surveys/informationforhouseholdsandindividuals/householdandindividualsurveys/ labourforcesurvey [Accessed 29 Oct 2020].

17 Office for National Statistics. Population estimates. Available: https://www.ons.gov. uk/peoplepopulationandcommunity/populationandmigration/populationestimates [Accessed 28 Sep 2020].

18 Vives A, González F, Moncada S, et al. Measuring precarious employment in times of crisis: the revised employment precariousness scale (EPRES) in Spain. Gac Sanit 2015;29:379-82

19 Office for National Statistics. Standard Occupational Classification - SOC 2020, 2020 Available: https://www.ons.gov.uk/methodology/classificationsandstandards/standard occupationalclassificationsoc/soc2020 [Accessed 29 Oct 2020].

20 Welsh Government. Welsh index of multiple deprivation. Available: https://gov.wales/ welsh-index-multiple-deprivation [Accessed 28 Sep 2020].

21 Welsh Government. National survey for Wales. Available: https://gov.wales/nationalsurvey-wales [Accessed 29 Oct 2020].

22 The Warwick-Edinburgh mental wellbeing scale (WEMWBS). Available: https:// warwick.ac.uk/fac/sci/med/research/platform/wemwbs [Accessed 29 Oct 2020].

23 Welsh Government. Leading Wales out of the coronavirus pandemic a framework for recovery, 2020. Available: https://gov.wales/sites/default/files/publications/ 2020-04/leading-wales-out-of-the-coronavirus-pandemic.pdf [Accessed 13 Oct 2020]

24 Bambra C, Riordan R, Ford J, et al. The COVID-19 pandemic and health inequalities. J Epidemiol Community Health 2020;74:964-8. 
25 Caldbick S, Labonte R, Mohindra KS, et al. Globalization and the rise of precarious employment: the new frontier for workplace health promotion. Glob Health Promot 2014;21:23-31.

26 Benach J, Vives A, Amable M, et al. Precarious employment: understanding an emerging social determinant of health. Annu Rev Public Health 2014;35:229-53.

27 Gray BJ, Grey CNB, Hookway A, et al. Differences in the impact of precarious employment on health across population subgroups: a scoping review. Perspect Public Health 2021;141:37-49.

28 Bartelink VHM, Zay Ya K, Guldbrandsson K, et al. Unemployment among young people and mental health: a systematic review. Scand J Public Health 2020;48:544-58.

29 Vancea M, Utzet M. How unemployment and precarious employment affect the health of young people: a scoping study on social determinants. Scand I Public Health 2017:45:73-84

30 Pierce M, Hope $\mathrm{H}$, Ford T, et al. Mental health before and during the COVID-19 pandemic: a longitudinal probability sample survey of the UK population. Lancet Psychiatry 2020;7:883-92.

31 Phillips JA, Nugent CN. Suicide and the great recession of 2007-2009: the role of economic factors in the 50 U.S. states. Soc Sci Med 2014;116:22-31.

32 Drydakis $\mathrm{N}$. The effect of unemployment on self-reported health and mental health in Greece from 2008 to 2013: a longitudinal study before and during the financial crisis. Soc Sci Med 2015;128:43-51.
33 Kaspersen SL, Pape K, Vie Gunnhild Å., et al. Health and unemployment: 14 years of follow-up on job loss in the Norwegian HUNT study. Eur J Public Health 2016;26:312-7.

34 Tinson A. Living in poverty was bad for your health before COVID-19, 2020. Available: https://www.health.org.uk/sites/default/files/2020-07/Living in poverty was bad for your health before COVID-19.pdf [Accessed 28 Sep 2020].

35 Marmot M. Health equity in England: the Marmot review 10 years on. BMJ 2020;368:m693

36 Aceves-Martins M, Cruickshank M, Fraser C, et al. Child food insecurity in the UK: a rapid review. Public Health Res 2018;6:1-162.

37 Lai ETC, Wickham S, Law C, et al. Poverty dynamics and health in late childhood in the UK: evidence from the millennium cohort study. Arch Dis Child 2019;104:1049-55.

$38 \mathrm{Kim} \mathrm{TJ}$, von dem Knesebeck $\mathrm{O}$. Is an insecure job better for health than having no job at all? A systematic review of studies investigating the health-related risks of both job insecurity and unemployment. BMC Public Health 2015;15:985.

39 Kim TJ, von dem Knesebeck O, insecurity Pjob. Perceived job insecurity, unemployment and depressive symptoms: a systematic review and metaanalysis of prospective observational studies. Int Arch Occup Environ Health 2016;89:561-73.

40 Karanikolos M, Mladovsky P, Cylus J, et al. Financial crisis, austerity, and health in Europe. The Lancet 2013;381:1323-31. 